\title{
Condicionamento osmótico na germinação de sementes de cássia-do-nordeste sob estresse hídrico, térmico e salino(1)
}

\author{
Helma Jeller(2) e Sonia Cristina Juliano Gualtierez de Andrade Perez ${ }^{(3)}$
}

\begin{abstract}
Resumo - O objetivo deste trabalho foi avaliar o efeito do condicionamento osmótico na germinação de sementes de Cassia excelsa Schrad. sob condições de estresse hídrico, térmico e salino. O condicionamento consistiu na imersão de quatro repetições de 25 sementes cada, em soluções de polietilenoglicol (PEG 6000) com potenciais osmóticos de -0,2, -0,4 e -0,6 MPa por 72, 96, 168 horas, respectivamente, e em água destilada por 48 horas, a $20^{\circ} \mathrm{C}$. Em seguida, as sementes foram colocadas para germinar em três condições: estresse hídrico, simulado com soluções de PEG a - $0,2,-0,4,-0,6$ e - $-0,8 \mathrm{MPa}$ a $27^{\circ} \mathrm{C}$; estresse térmico, sob temperaturas subótima $\left(12^{\circ} \mathrm{C}\right)$ e supra-ótima $\left(39^{\circ} \mathrm{C}\right)$ em água destilada; estresse salino, em soluções de $\mathrm{NaCl}$ a $-0,2,-0,4,-0,6,-0,8,-1,0,-1,2$ e $-1,4 \mathrm{MPa}$ a $27^{\circ} \mathrm{C}$. Foram avaliadas as porcentagens de germinação e tempos médios de emergência da radícula. A técnica de condicionamento osmótico com PEG ou com água destilada foi eficiente em aumentar a germinabilidade sob estresse hídrico e sob estresse térmico. A porcentagem de germinação sob estresse salino aumentou com o condicionamento com PEG, porém não houve redução no tempo de germinação.
\end{abstract}

Termos para indexação: Cassia excelsa, solução, embebição, salinidade.

Priming in cássia-do-nordeste seeds under water, thermic and salt stress

\begin{abstract}
The objective of this work was to evaluate osmoconditioning effects on seed germination of Cassia excelsa Schrad. under water, thermic and salt stress. Four replicates of 25 seeds were placed to imbibe in PEG solutions with osmotic potentials of $-0.2,-0.4$ and $-0.6 \mathrm{MPa}$ during 72,96 , 168 hours, respectively and in distilled water for 48 hours, at $20^{\circ} \mathrm{C}$. After that, the seeds were placed to germinate in conditions of water stress, ranging from -0.2 to $-0.8 \mathrm{MPa}$ at $27^{\circ} \mathrm{C}$, in thermic stress conditions at $12^{\circ} \mathrm{C}$ and $39^{\circ} \mathrm{C}$ and in $\mathrm{NaCl}$ solutions with osmotic potential ranging from -0.2 to $-1.4 \mathrm{MPa}$ at $27^{\circ} \mathrm{C}$, simulating salt stress. The parameters evaluated were the number of germinated seeds and the rate of radicle emergence. The osmoconditioning technique was efficient to increase the germinability under water and thermic stress, when PEG or distilled water was used. The germination percentage under salt stress increased with PEG conditioning, without increase in the germination rate.
\end{abstract}

Index terms: Cassia excelsa, solutions, soaking, salinity.

\section{Introdução}

Fatores que interferem na germinação de sementes de espécies arbóreas tropicais podem ser controlados geneticamente ou pelo meio ambiente. Entre

${ }^{(1)}$ Aceito para publicação em 5 de junho de 2003.

Extraído da tese de doutorado do primeiro autor apresentada à Universidade Federal de São Carlos (UFSCar), São Carlos, SP

(2) Universidade Federal de Mato Grosso do Sul, Laboratório de Botânica, Caixa Postal 549, CEP 79070-900 Campo Grande, MS. E-mail: helma@fes.br

(3) UFSCar, Dep. de Botânica, Caixa Postal 676, CEP 13565-905 São Carlos, SP. E-mail: dscp@ power.ufscar.br os fatores controlados pelo meio ambiente, o mais crítico é a ausência de condições ótimas para a germinação e o estabelecimento de plântulas (Barbedo \& Marcos Filho, 1998).

Tratamentos pré-germinativos ou pós-colheita têm sido realizados com o objetivo de reduzir e evitar a exposição prolongada das sementes às condições de estresse que podem ocorrer durante a semeadura em áreas degradadas, ocasionando a deterioração prematura em campo (Khan, 1992).

Os tratamentos pré-germinativos das sementes são usados para incrementar a germinação e melhorar a uniformidade de emergência (Warren \& Bennett, 
1997). Entre eles, pode-se citar o condicionamento osmótico, técnica que permite o controle da hidratação das sementes, suficiente para permitir eventos metabólicos pré-germinativos, porém insuficiente para permitir a emissão da radícula (Bradford, 1986). As sementes são imersas em soluções, utilizando-se agentes osmóticos, sob temperaturas específicas e por períodos definidos, e absorvem água até o ponto de atingirem o equilíbrio com o potencial osmótico da solução (Bray, 1995).

Durante o condicionamento osmótico, a semente hidrata-se lentamente, o que permite maior tempo para a reparação ou reorganização das membranas, dando possibilidade aos tecidos de se desenvolverem de maneira mais ordenada, reduzindo os riscos de danos ao eixo embrionário causados por embebição rápida (Smith \& Coob, 1992).

Quando o condicionamento das sementes é favorável, ocorre o processo de mobilização de reservas, ativação e síntese-de-novo de algumas enzimas, e início e aumento da síntese de DNA e RNA, disponibilizando às sementes os precursores utilizados na síntese de macromoléculas. Essas sínteses podem estar relacionadas à remoção de certos agentes inibidores da germinação, como o ácido abscíssico (ABA), ou à produção de fatores promotores, como o ácido giberélico. O estresse hídrico nas sementes aumenta a produção de $\mathrm{ABA}$ e induz à dormência, enquanto o condicionamento osmótico pode reduzir a produção de ABA (Khan, 1992).

A técnica de condicionamento osmótico em sementes possibilita a obtenção de maior porcentagem de germinação, particularmente em condições adversas, como a baixa disponibilidade hídrica, níveis elevados de salinidade e temperaturas subótima ou supra-ótima. O aumento do nível de tolerância a estresses foi conseguido por Taylor et al. (1998) e Patane (2000), com germinação mais rápida quando as sementes foram submetidas a temperaturas mais baixas que a ótima. Yoon et al. (1997) e Nascimento et al. (2001) obtiveram germinação mais rápida em temperaturas desfavoráveis, acima da ótima. Prisco et al. (1992) e Fernandes et al. (1994) conseguiram melhores respostas de germinação sob condições de déficit hídrico, e Passam \& Kakouriotis (1994) obtiveram melhores respostas sob condições de estresse salino.
Os trabalhos referentes à técnica de condicionamento osmótico são bastante promissores (Bray, 1995; Nascimento, 1998), porém, se restringem à utilização de sementes de espécies cultivadas. O uso dessa técnica com espécies florestais nativas é ainda muito limitado e por essa razão, são necessárias informações sobre a utilização de técnicas que aumentem o poder germinativo dessas sementes, sob condições adversas, de modo a contribuir com programas de reflorestamento de áreas degradadas ou de recomposição de matas nativas.

A espécie Cassia excelsa Schrad. apresenta porte arbóreo, é encontrada no cerrado e na caatinga do Nordeste brasileiro, e é empregada em paisagismo. Também é utilizada na arborização urbana no Sudeste brasileiro, e pode ser indicada para plantios associados a outras espécies, destinadas à recomposição de áreas degradadas. Porém, suas sementes apresentam baixa germinabilidade devido à restrição imposta pelo tegumento impermeável, o que restringe seu uso direto ou sob condições adversas, sem a utilização de tratamento pré-germinativos.

O objetivo deste trabalho foi avaliar o efeito do condicionamento osmótico na germinação de sementes de Cassia excelsa sob condições de estresse hídrico, térmico e salino.

\section{Material e Métodos}

O trabalho foi realizado no Laboratório de Botânica do Departamento de Biologia da Universidade Federal de Mato Grosso do Sul (UFMS), Campo Grande, MS. Foram utilizadas sementes de cássia-do-nordeste coletadas no Campus da Universidade Estadual Paulista (Unesp) de Jaboticabal, SP, em julho de 1997 e armazenadas em geladeira (em torno de $5^{\circ} \mathrm{C}$ ) em vidros tampados. As sementes, com teor de umidade de $11 \%$, foram inicialmente selecionadas a fim de se obter uniformidade quanto à coloração, tamanho e estado de conservação. Como as sementes dessa espécie apresentam tegumento duro e impermeável, antes do condicionamento osmótico, utilizouse ácido sulfúrico concentrado, durante 25 minutos (Jeller \& Perez, 1999), para superar a dormência mecânica, uniformizar e acelerar o processo germinativo. A constância de temperatura nos testes realizados foi obtida por meio do uso de incubadora (tipo BOD), com precisão de $\pm 0,5 \%$, na ausência de luz. As concentrações de polietilenoglicol (PEG 6000) utilizadas no preparo das soluções de diferentes potenciais osmóticos foram definidas em razão da temperatura, conforme Villela et al. (1991). 
O condicionamento osmótico foi realizado por meio da imersão das sementes em $30 \mathrm{~mL}$ de água destilada e em $30 \mathrm{~mL}$ de soluções de PEG a -0,2, -0,4 e -0,6 MPa até a emergência da radícula, que correspondeu a períodos de 48, 72, 96 e 168 horas, respectivamente (Jeller \& Perez, 2003), a $20^{\circ} \mathrm{C}$.

O estresse hídrico foi avaliado em quatro subamostras de 400 sementes condicionadas que foram lavadas rapidamente em água corrente, para remover a solução de PEG aderida às sementes, secadas superficialmente e colocadas para germinar em placas de Petri forradas por duas folhas de papel-filtro (quatro repetições de 25 unidades), umedecido com $6 \mathrm{~mL}$ de soluções de PEG a -0,2, -0,4, - 0,6 e $-0,8 \mathrm{MPa}$, a $27^{\circ} \mathrm{C}$. Os potenciais osmóticos foram obtidos tomando-se por base os resultados dos testes de germinação de sementes de cássia-do-nordeste sob estresse hídrico em Jeller \& Perez (2001). O tratamento controle consistiu de 400 sementes colocadas para germinar em placas de Petri, forradas por duas folhas de papel-filtro umedecidas com $6 \mathrm{~mL}$ de soluções de PEG a -0,2, - 0,4 , $-0,6$ e $-0,8 \mathrm{MPa}+0,2 \%$ de fungicida (Captan). As placas foram fechadas com filme de PVC, tampadas e colocadas para germinar em temperatura ótima $\left(27^{\circ} \mathrm{C}\right)$ conforme Jeller \& Perez (1999).

O estresse térmico foi avaliado em quatro subamostras de 200 sementes condicionadas, lavadas em água corrente, para remover a solução de PEG aderida às sementes. Em seguida, foram secadas superficialmente e colocadas para germinar em placas de Petri, forradas internamente com duas folhas de papel-filtro (quatro repetições de 25 unidades por placa) umedecido com $6 \mathrm{~mL}$ de água destilada e mantidas a $12^{\circ} \mathrm{C}$ e $39^{\circ} \mathrm{C}$. As temperaturas foram selecionadas considerando-se os resultados de testes de germinação de sementes de cássia-do-nordeste sob diferentes temperaturas, obtidos por Jeller \& Perez (1999). No tratamento controle, sementes não condicionadas foram colocadas para germinar em placas de Petri, forradas com duas folhas de papel-filtro umedecidas com $6 \mathrm{~mL}$ de água destilada $+0,2 \%$ de fungicida, sob temperaturas de $12^{\circ} \mathrm{C}$ e $39^{\circ} \mathrm{C}$, consideradas subótima e supra-ótima, respectivamente.

O estresse salino foi avaliado em quatro subamostras de 700 sementes condicionadas, lavadas rapidamente em água corrente, para remover a solução de PEG aderida às sementes. Em seguida, as sementes foram secadas superficialmente e colocadas para germinar em placas de Petri forradas com duas folhas de papel-filtro (quatro repetições de 25 unidades por placa) umedecido com $6 \mathrm{~mL}$ de soluções de $\mathrm{NaCl}-0,2,-0,4,-0,6,-0,8,-1,0,-1,2$ e - $1,4 \mathrm{MPa}$ a $27^{\circ} \mathrm{C}$. Os potenciais osmóticos foram selecionados considerando-se os resultados de testes de germinação de se- mentes de cássia-do-nordeste sob estresse salino, obtidos por Jeller \& Perez (2001). O controle consistiu de um lote de 700 sementes colocadas para germinar em placas de Petri, forradas com duas folhas de papel-filtro umedecidas com $6 \mathrm{~mL}$ da solução de $\mathrm{NaCl}$ a - $0,2,-0,4,-0,6,-0,8,-1,0$, $-1,2$ e $-1,4 \mathrm{MPa}+0,2 \%$ de fungicida. As placas de Petri, fechadas com filme de PVC, foram colocadas sob temperatura de $27^{\circ} \mathrm{C}$.

O delineamento estatístico utilizado foi inteiramente casualizado, com quatro repetições de 25 sementes para cada estudo proposto. Avaliou-se a quantidade de sementes germinadas, obtendo-se assim as porcentagens e tempos médios de emergência da radícula, conforme Labouriau (1983). As comparações dos valores médios de porcentagem (transformados para arc sen $(\mathrm{P} / 100)^{0,5}$ ) e tempo de emergência foram feitas por meio da análise de variância, em esquema fatorial de $4 \times 4$ (potenciais de condicionamento $\mathrm{x}$ potenciais do meio germinativo) para o estresse hídrico; 4x2 (potenciais de condicionamento $\mathrm{x}$ temperaturas) para o estresse térmico; e de $4 \times 7$ (potenciais de condicionamento $\mathrm{x}$ potenciais do meio germinativo) para o estresse salino. A comparação das médias foi feita pelo teste de Tukey, a 5\% de probabilidade.

\section{Resultados e Discussão}

Sob condições de estresse hídrico, as sementes de cássia-do-nordeste apresentaram redução gradativa da germinabilidade e da velocidade de germinação quando o potencial osmótico da solução do meio germinativo foi reduzido de $-0,2$ a $-0,8 \mathrm{MPa}$, tanto nas sementes que foram condicionadas em água destilada ou em diferentes potenciais osmóticos das soluções de PEG, quanto nas que não foram condicionadas (controle) (Figura 1).

A análise de variância dos valores médios de porcentagem e tempo de germinação das sementes sob estresse hídrico, após o condicionamento osmótico, indicou que o potencial do meio germinativo, o condicionamento em água destilada e nos diferentes potenciais osmóticos das soluções de PEG e a interação entre estes fatores foram significativas em relação à germinação das sementes (Tabela 1).

Não houve diferença significativa entre a porcentagem de germinação das sementes quando submetidas ao maior potencial osmótico do meio germinativo testado (-0,2 $\mathrm{MPa})$, e as sementes que foram condicionadas em água destilada ou nos diferentes potenciais osmóticos das soluções de PEG, e 


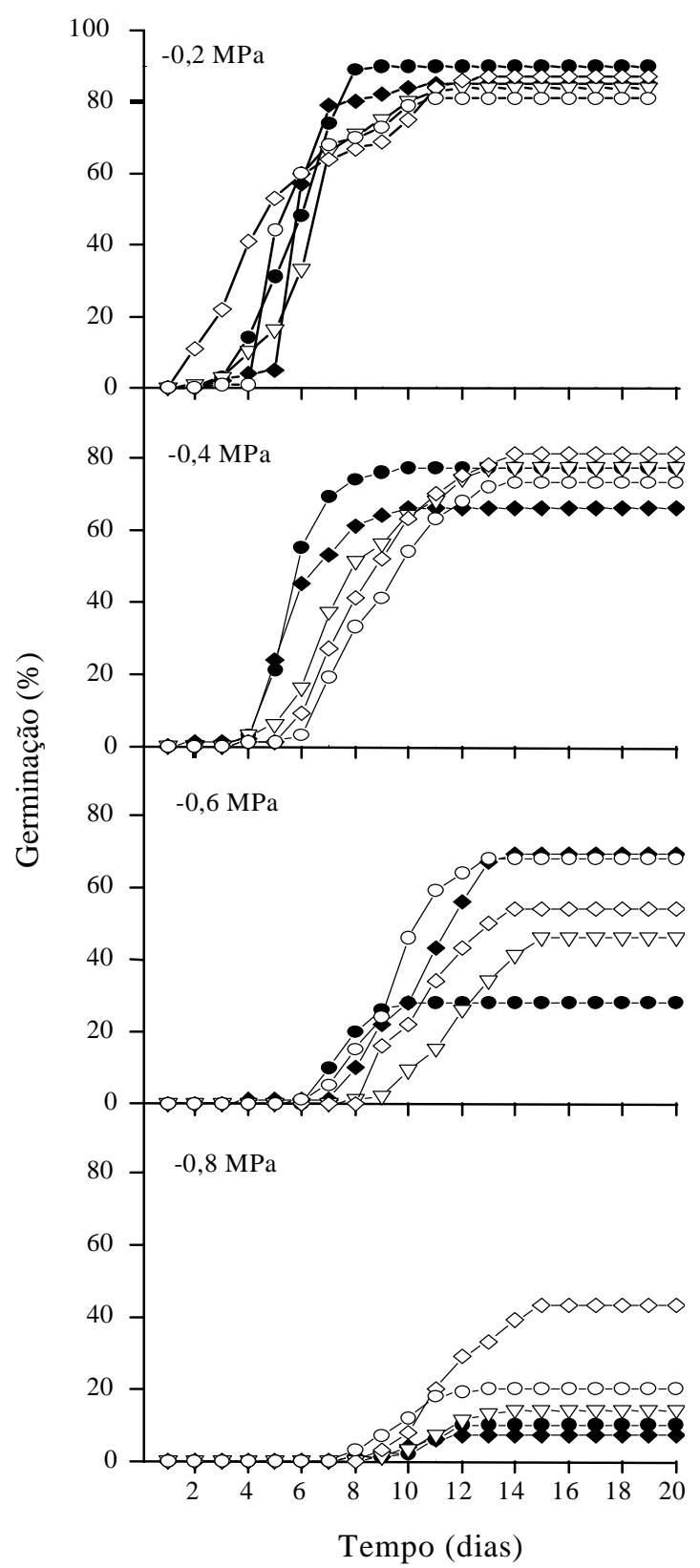

Figura 1. Distribuição no tempo da porcentagem acumulada de germinação de sementes de Cassia excelsa submetidas a estresse hídrico simulado por soluções de PEG 6000 com potenciais osmóticos de -0,2, -0,4, - -0,6 e $-0,8 \mathrm{MPa}$, a $27^{\circ} \mathrm{C}$, após condicionamento em soluções de PEG 6000 a $-0,2(\nabla),-0,4(\diamond)$ e $-0,6 \mathrm{MPa}(\bigcirc)$ e água destilada $(\boldsymbol{\vee})$, a $20^{\circ} \mathrm{C}$. Controle $(\boldsymbol{\bullet})$. nas sementes que não foram condicionadas. Comportamento semelhante foi apresentado pelas sementes quando se reduziu o potencial osmótico do meio germinativo de -0,2 MPa para -0,4 MPa.

Portanto, a água destilada pode ser utilizada com eficiência no condicionamento osmótico das sementes, pois não se observou efeito prejudicial em virtude da rápida embebição. O mesmo foi verificado por Lopes et al. (1996) e Braccini et al. (1999) em sementes de soja. Khan (1992) também constatou que as modificações fisiológicas e bioquímicas que ocorrem nas sementes condicionadas em água ou condicionadas osmoticamente são semelhantes. Essas mudanças incluem a síntese de macromoléculas, a atividade de várias enzimas, aumento do vigor e a superação da dormência.

Quando o potencial osmótico do meio germinativo foi reduzido para $-0,6 \mathrm{MPa}$, somente as sementes que foram condicionadas em água destilada ou a - $-0,6 \mathrm{MPa}$ da solução do meio germinativo apresentaram porcentuais elevados de germinação, sendo $69 \%$ e $68 \%$, respectivamente, diferindo significativamente daquelas que não foram condicionadas (28\%). As sementes que foram condicionadas a - $0,2 \mathrm{MPa}$ e a $-0,4 \mathrm{MPa}$ apresentaram valores superiores ao do controle ( $46 \%$ e $54 \%$, respectivamente), mas sem diferenças significativas entre si. Valores inferiores de porcentagem de germinação foram obtidos pelas sementes que germinaram a $-0,8 \mathrm{MPa}$, tanto nas que não foram condicionadas ( $10 \%$ de germinação), quanto nas que foram condicionadas em água destilada, ou em soluções de PEG a -0,2 MPa e a -0,6 MPa, que não apresentaram diferenças significativas entre si. Porém, quando o condicionamento osmótico foi realizado a - $0,4 \mathrm{MPa}$, a técnica mostrouse eficiente para elevar o índice de $10 \%$ para $43 \%$, diferença considerada estatisticamente significativa.

Portanto, com o uso do condicionamento osmótico, é possível se obter índice elevado de germinação quando as sementes forem semeadas diretamente em solos com déficit hídrico, com potencial osmótico menor que -0,4 MPa.

Com o aumento da intensidade do estresse hídrico, nas sementes que não foram condicionadas, pode ocorrer uma indução à dormência, por causa do aumento de ácido abscíssico, que, com o condi- 
cionamento osmótico, pode desaparecer (Khan, 1992). Desta forma, no potencial de -0,4 MPa, as sementes condicionadas não perderam a viabilidade e nem entraram em dormência, possibilitando maiores chances de sobrevivência, quando sujeitas a ambientes com déficit hídrico.

Conforme Bewley \& Black (1994), a ação enzimática nas células vizinhas à radícula pode estar associada ao aumento da atividade da enzima endo- $\beta$-mannanase no endosperma, o qual seria responsável pela hidrólise de galactomanano, polissacarídeo constituinte das paredes celulares do endosperma e cuja atividade é estimulada pela ação de giberelinas, que apresentam produção limitada sob condição de estresse hídrico. Segundo Nascimento et al. (2000), o aumento da porcentagem de germinação nestas condições se deve ao incremento da atividade desta enzima no início do condicionamento osmótico.

Uma das principais vantagens do condicionamento osmótico relatado por Warren \& Bennett (1997) seria promover uma emergência mais rápida e uniforme das sementes no campo, proporcionando um incremento no desenvolvimento das plântulas, mesmo em condições adversas. Lopes et al. (1996) sugerem que o tempo de germinação pode ser reduzido sob condições de estresse hídrico e que sementes condicionadas apresentam maior viabilidade e vigor em relação às não condicionadas. $\mathrm{O}$ mesmo não pôde ser observado nas sementes de cássia-do-nordeste condicionadas, quando comparadas com sementes não condicionadas. As sementes não condicionadas apresentaram germinação mais rápida. $\mathrm{O}$ atraso da germinação, após o condicionamento osmótico, pode significar perda de vigor ou ainda, segundo Lanteri et al. (1998), falhas no mecanismo de reparo que atua no processo de deterioração das sementes.
Quando as sementes foram colocadas para germinar em temperatura subótima $\left(12^{\circ} \mathrm{C}\right)$ ou supra-ótima $\left(39^{\circ} \mathrm{C}\right)$ apresentaram baixa germinabilidade, conforme os resultados da porcentagem acumulada de germinação, em razão do tempo (com 4,5\% e 12\%, respectivamente), apresentados pelas sementes que não foram condicionadas (Figura 2).

A análise de variância da porcentagem de germinação das sementes sob estresse térmico indicou que o condicionamento osmótico em diferentes potenciais osmóticos e a temperatura do meio germinativo tiveram efeito significativo na germinação das sementes, porém, a interação entre esses fatores não foi significativa na porcentagem final de germinação. Esses dois fatores e sua interação tiveram efeitos significativos no tempo de germinação das sementes (Tabela 2).

Após o condicionamento das sementes e sob temperatura subótima $\left(12^{\circ} \mathrm{C}\right)$, foi verificada uma tendência de germinação em menor tempo e maior porcentagem, à medida que o potencial osmótico das soluções de PEG foi reduzido. O condicionamento foi eficiente em aumentar o desempenho germinativo, quando comparado ao baixo desempenho das sementes que não foram condicionadas (Tabela 2). Estes resultados estão de acordo com os de Bradford (1986) e são semelhantes aos de Zengh et al. (1994) e Taylor et al. (1998), em que sementes condicionadas osmoticamente apresentam maior taxa de germinação e vigor, em relação às não tratadas, quando expostas a condições de temperaturas subótimas. Assim, é possível introduzir esta espécie em regiões de climas mais frios, como por exemplo, no Sul do país, com a utilização de sementes condicionadas em água ou nos potenciais osmóticos de PEG testados.

Tabela 1. Porcentagem e tempo de germinação (dias) de sementes de Cassia excelsa submetidas ao estresse hídrico simulado por soluções de PEG 6000, após o condicionamento em água destilada e em diferentes potenciais osmóticos das soluções de PEG 6000 a $20^{\circ} \mathrm{C}^{(1)}$.

\begin{tabular}{|c|c|c|c|c|c|c|c|c|}
\hline \multirow[t]{3}{*}{ Condicionamento } & \multicolumn{8}{|c|}{ Potencial osmótico do meio germinativo (MPa) } \\
\hline & \multicolumn{2}{|c|}{$-0,2$} & \multicolumn{2}{|c|}{$-0,4$} & \multicolumn{2}{|c|}{$-0,6$} & \multicolumn{2}{|c|}{$-0,8$} \\
\hline & $(\%)$ & (Dias) & $(\%)$ & (Dias) & $(\%)$ & (Dias) & $(\%)$ & (Dias) \\
\hline Água & $85 \mathrm{ab}$ & $6,37 a b$ & 66abcd & $7,15 \mathrm{abc}$ & 69abcd & $10,75 \mathrm{ef}$ & $7 \mathrm{~h}$ & $10,13 \mathrm{def}$ \\
\hline PEG - $0,2 \mathrm{MPa}$ & $84 a b$ & $6,76 \mathrm{ab}$ & 77abcd & 8,15 abcd & $46 \mathrm{cdef}$ & $12,11 \mathrm{f}$ & $14 \mathrm{fgh}$ & $11,75 \mathrm{f}$ \\
\hline PEG -0,4MPa & $87 a b$ & $6,75 \mathrm{ab}$ & $81 \mathrm{ab}$ & 8,85 bcde & 54bcde & $10,94 \mathrm{ef}$ & 43def & $12,03 \mathrm{f}$ \\
\hline PEG -0,6MPa & $81 \mathrm{ab}$ & $7,19 \mathrm{abc}$ & 73abcd & 9,12 cde & 68abcd & $10,00 \mathrm{def}$ & 20efgh & 9,96def \\
\hline Controle & $90 \mathrm{a}$ & $6,11 \mathrm{a}$ & 77abcd & $7,09 \mathrm{abc}$ & $28 \mathrm{efg}$ & $8,04 \mathrm{abcd}$ & $10 \mathrm{gh}$ & $11,19 \mathrm{ef}$ \\
\hline
\end{tabular}

${ }^{(1)}$ Médias seguidas pela mesma letra não diferem entre si pelo teste de Tukey, a $5 \%$ de probabilidade. 


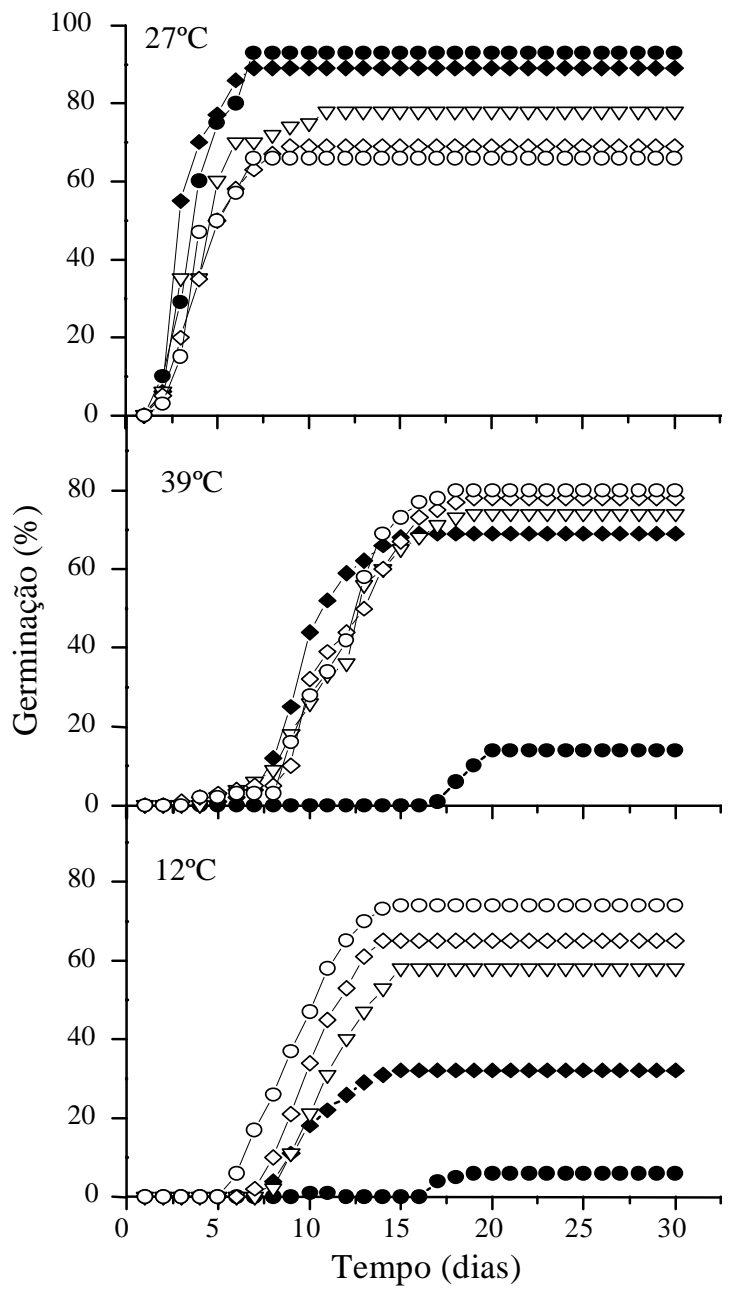

Figura 2. Distribuição no tempo da porcentagem acumulada de germinação de sementes de Cassia excelsa submetidas a estresse térmico $\left(12^{\circ} \mathrm{C}\right.$ e $\left.39^{\circ} \mathrm{C}\right)$ e à temperatura ótima $\left(27^{\circ} \mathrm{C}\right)$, após condicionamento em soluções de PEG 6000 a $-0,2(\nabla),-0,4(\diamond),-0,6 \mathrm{MPa}(\bigcirc)$ e água destilada $(\checkmark)$, a $20^{\circ} \mathrm{C}$. Controle $(\boldsymbol{\odot})$.
Em todos os potenciais testados, verificou-se germinação mais rápida das sementes condicionadas. Portanto, nas sementes condicionadas em água destilada ou nos diferentes potenciais osmóticos de PEG, a porcentagem de germinação foi superior a do controle, evidenciando que sementes condicionadas apresentam um melhor desempenho quando submetidas a estresses, como já foi comprovado com sementes de hortaliças (Gray et al., 1992; Murray \& Swensen, 1992; Trigo et al., 1999).

O condicionamento osmótico foi eficiente em reverter o processo de deterioração que acontece nas sementes em temperaturas supra-ótimas, permitindo maior atividade metabólica pré-germinativa e conseqüentemente, incremento no desenvolvimento das plântulas. O efeito benéfico do condicionamento osmótico também pôde ser evidenciado pelo baixo desempenho das sementes que não foram condicionadas, que apresentaram emergência bastante reduzida, comparada com as sementes condicionadas, indicando que o efeito benéfico proporcionado pelo condicionamento osmótico foi consequiência de mecanismos de reparo que atuam no processo de deterioração das sementes, conforme Lanteri et al. (1998).

Segundo Nascimento et al. (2001), sementes condicionadas podem superar o efeito inibitório de temperatura elevada por causa do aumento da atividade das enzimas endo-beta-mananase, o que provoca degradação das paredes celulares do endosperma, superando assim a termodormência.

O condicionamento osmótico realizado com água destilada, de um modo geral, proporcionou incrementos no desempenho das sementes em condições de estresse térmico, tanto em temperatura subótima quanto na supra-ótima, revelando que este também é um tratamento eficiente. A diferença na porcentagem e no tempo de germinação entre as sementes condicionadas e não condicionadas ocorre porque durante o condicionamento osmótico são iniciados vários processos bioquímicos, além de reparos de danos ao sistema de membranas e do aparato res-

Tabela 2. Porcentagem e tempo de germinação (dias) de sementes de Cassia excelsa submetidas ao estresse térmico $\left(12^{\circ} \mathrm{C}\right.$ e $\left.39^{\circ} \mathrm{C}\right)$ e à temperatura ótima $\left(27^{\circ} \mathrm{C}\right)$, após o condicionamento em água destilada e em soluções de PEG 6000 a $20^{\circ} \mathrm{C}^{(1)}$

\begin{tabular}{|c|c|c|c|c|c|c|}
\hline \multirow[t]{2}{*}{ Condicionamento } & \multicolumn{2}{|c|}{$12^{\circ} \mathrm{C}$} & \multicolumn{2}{|c|}{$39^{\circ} \mathrm{C}$} & \multicolumn{2}{|c|}{$27^{\circ} \mathrm{C}$} \\
\hline & $(\%)$ & (Dias) & $(\%)$ & (Dias) & $(\%)$ & (Dias) \\
\hline Água & $32 \mathrm{bc}$ & $10,40 \mathrm{ab}$ & $69 a$ & $10,30 \mathrm{ab}$ & $89 a$ & $5,52 \mathrm{a}$ \\
\hline PEG - $0,2 \mathrm{MPa}$ & $58 \mathrm{ab}$ & $11,43 \mathrm{ab}$ & $74 \mathrm{a}$ & $11,73 b$ & $78 \mathrm{a}$ & $6,88 \mathrm{a}$ \\
\hline PEG -0,4MPa & $65 \mathrm{a}$ & $10,51 \mathrm{ab}$ & $78 \mathrm{a}$ & $10,94 b$ & $69 a$ & $7,20 \mathrm{a}$ \\
\hline PEG -0,6MPa & $74 \mathrm{a}$ & $9,61 \mathrm{a}$ & $88 \mathrm{a}$ & $11,99 \mathrm{~b}$ & $66 a$ & $7,65 \mathrm{a}$ \\
\hline Controle & $4,5 \mathrm{~d}$ & $16,83 \mathrm{c}$ & $14 \mathrm{~cd}$ & $18,77 \mathrm{c}$ & $93 a$ & $7,75 \mathrm{a}$ \\
\hline
\end{tabular}

${ }^{(1)}$ Médias seguidas pela mesma letra não diferem entre si pelo teste de Tukey, a $5 \%$ de probabilidade. 
piratório. Assim, quando as sementes são submetidas ao condicionamento osmótico, obtêm-se crescimento mais rápido do embrião e incrementos no poder germinativo e no vigor (Khan, 1992; Sung \& Chang, 1993; McDonald, 1998).

Sob condições de estresse salino simulado pelas soluções de $\mathrm{NaCl}$, as sementes apresentaram uma progressiva redução da germinabilidade e aumento do tempo de germinação, quando se reduziu o potencial osmótico das soluções do meio germinativo de -0,2 para -1,4 MPa, constatado tanto nas sementes que não foram condicionadas (controle) como nas que foram condicionadas em água destilada ou nos diferentes potenciais osmóticos das soluções de PEG (Figura 3 e Tabela 3).

A análise de variância da porcentagem de germinação das sementes, sob estresse salino, indicou que o condicionamento das sementes em água destilada e em diferentes potenciais osmóticos das soluções de PEG, como também o potencial osmótico do meio germinativo e a interação entre estes fatores foram estatisticamente significativas em relação à germinação das sementes (Tabela 3). A análise de variância para o tempo de germinação indica que o condicionamento osmótico com água destilada, ou em diferentes potenciais osmóticos das soluções de
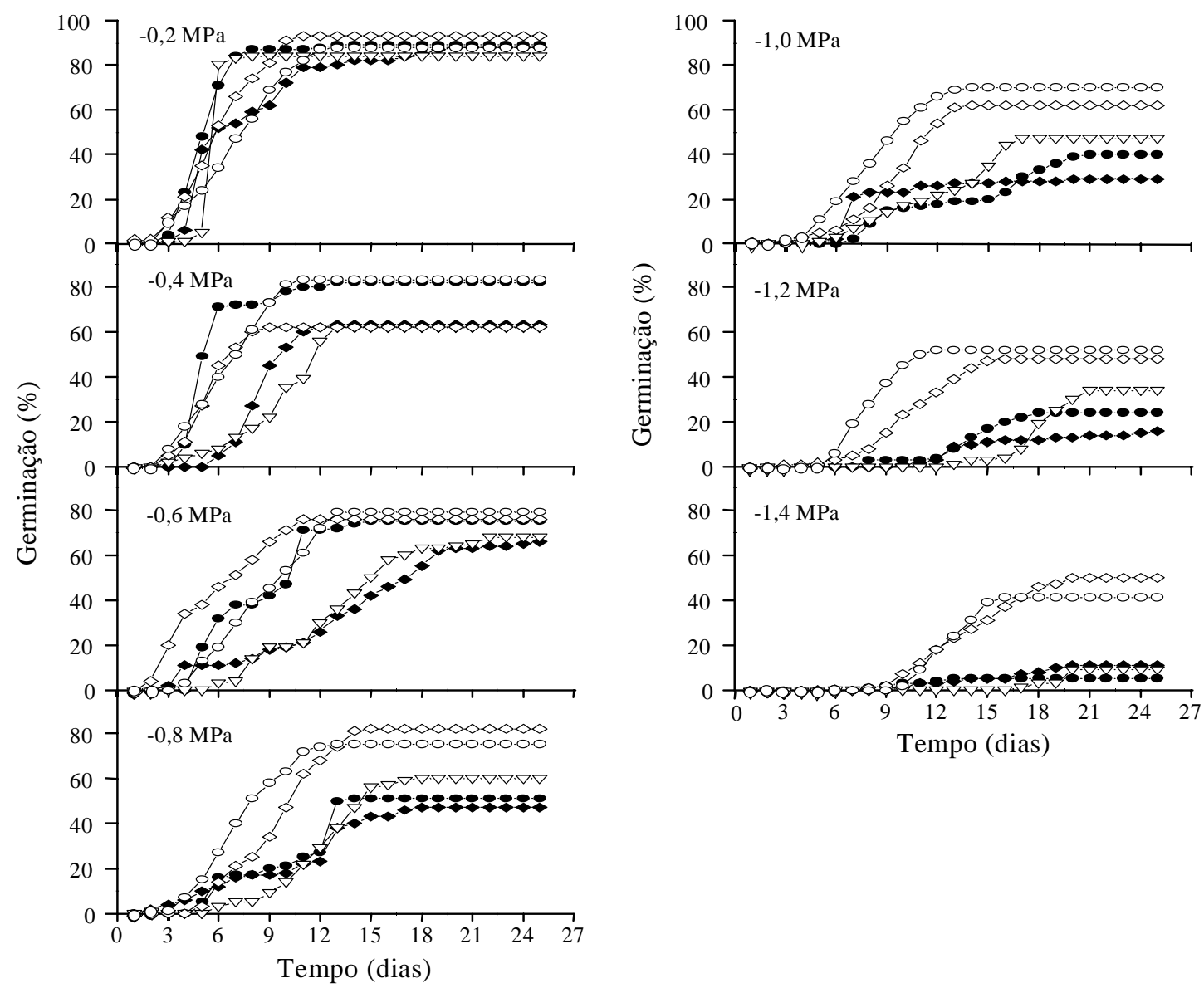

Figura 3. Distribuição no tempo da porcentagem acumulada de germinação de sementes de Cassia excelsa submetidas a estresse salino simulado por soluções de $\mathrm{NaCl}$ com potenciais osmóticos de $-0,2$ a $-1,4 \mathrm{MPa}$, a $27^{\circ} \mathrm{C}$, após condicionamento em soluções de PEG 6000 a $-0,2(\nabla),-0,4(\diamond),-0,6 \mathrm{MPa}(\bigcirc)$ e água destilada $(\diamond)$, a $20^{\circ} \mathrm{C}$. Controle 
Tabela 3. Porcentagem e tempo de germinação (dias) de sementes de Cassia excelsa submetidas ao estresse salino simulado com soluções de $\mathrm{NaCl}$, após o condicionamento em água destilada e em soluções de PEG 6000 a $20^{\circ} \mathrm{C}^{(1)}$.

\begin{tabular}{|c|c|c|c|c|c|c|c|}
\hline \multirow[t]{2}{*}{ Condicionamento } & \multicolumn{7}{|c|}{ Potencial osmótico do meio germinativo $(\mathrm{NaCl})(\mathrm{MPa})$} \\
\hline & $-0,2$ & $-0,4$ & $-0,6$ & $-0,8$ & $-1,0$ & $-1,2$ & $-1,4$ \\
\hline & \multicolumn{7}{|c|}{ Germinação (\%) } \\
\hline Água & $88 \mathrm{ab}$ & 63abcdefgh & 63abcdefgh & 47efghi & 29ijk & $16 \mathrm{jkl}$ & $11 \mathrm{jkl}$ \\
\hline PEG -0,2MPa & $89 \mathrm{a}$ & 62abcdefgh & 68abcdefg & 60cdefgh & 47 efghi & 34hijk & $9 \mathrm{kl}$ \\
\hline PEG - $0,4 \mathrm{MPa}$ & $93 \mathrm{a}$ & 62abcdefgh & 76abcdef & $82 \mathrm{abcd}$ & 62abcdefgh & 48efghi & 50efghi \\
\hline PEG -0,6MPa & $88 \mathrm{ab}$ & $83 \mathrm{abc}$ & 79abcde & $75 \mathrm{abcdef}$ & 70abcdefg & 52defghi & 41 fghi \\
\hline Controle & $89 \mathrm{a}$ & $82 \mathrm{abcd}$ & $75 \mathrm{abcdef}$ & 51efghi & 40ghij & $24 \mathrm{ijkl}$ & $5 \mathrm{k}$ \\
\hline & \multicolumn{7}{|c|}{ Tempo de germinação (dias) } \\
\hline Água & $6,72 \mathrm{a}$ & 8,84 abcd & $13,18 \mathrm{abcd}$ & $8,36 \mathrm{abc}$ & $13,42 \mathrm{abcd}$ & $14,58 \mathrm{abcd}$ & $14,96 \mathrm{abcd}$ \\
\hline PEG -0,2MPa & $6,06 a$ & $11,80 \mathrm{abcd}$ & $13,42 \mathrm{abcd}$ & $12,09 \mathrm{abcd}$ & $12,26 \mathrm{abcd}$ & $18,41 \mathrm{~cd}$ & $18,33 \mathrm{bcd}$ \\
\hline PEG -0,4MPa & $6,39 a$ & $6,77 \mathrm{a}$ & $5,93 \mathrm{a}$ & $10,58 \mathrm{abcd}$ & $9,74 \mathrm{abcd}$ & $10,74 \mathrm{abcd}$ & $14,02 \mathrm{abcd}$ \\
\hline PEG $-0,6 \mathrm{MPa}$ & $7,26 \mathrm{a}$ & $6,66 \mathrm{a}$ & $8,79 \mathrm{abcd}$ & $7,48 \mathrm{a}$ & $9,39 \mathrm{abcd}$ & $8,35 \mathrm{ab}$ & $13,02 \mathrm{abcd}$ \\
\hline Controle & $5,47 \mathrm{a}$ & $5,86 \mathrm{a}$ & $8,26 \mathrm{ab}$ & $10,20 \mathrm{abcd}$ & $13,81 \mathrm{abcd}$ & $13,89 \mathrm{abcd}$ & $19,87 \mathrm{~d}$ \\
\hline
\end{tabular}

PEG, e o potencial osmótico do meio germinativo afetam significativamente o tempo de germinação das sementes, mas a interação entre estes fatores não foi estatisticamente significativa neste processo (Tabela 3).

Não houve diferença estatística significativa entre os valores médios de porcentagem de germinação das sementes submetidas ao estresse salino nos potenciais de -0,2 a -0,6 MPa. Nestes potenciais, o condicionamento em água destilada não foi diferente do condicionamento com soluções de PEG. Também não houve diferença entre as sementes condicionadas e as do tratamento controle (Tabela 3 ). No potencial osmótico de $-0,8 \mathrm{MPa}$, a resposta das sementes ao condicionamento osmótico feito com PEG a -0,4 MPa foi semelhante às respostas obtidas nos potenciais de -0,2 MPa a -0,6 MPa e superior à das sementes não condicionadas e condicionadas em água destilada.

$\mathrm{O}$ condicionamento das sementes nos potenciais osmóticos de -0,4 e -0,6 MPa das soluções de PEG foi eficiente em superar o estresse salino do meio germinativo de -1,0 a -1,4 MPa. Isto ocorreu porque a embebição sob baixos potenciais hídricos se processou mais lentamente. Tal fato permitiu um maior tempo para a reparação ou reorganização das membranas, possibilitando que os tecidos se desenvolvessem de forma mais ordenada, reduzindo os riscos de ocorrência de danos ao eixo embrionário, causado pela rápida embebição (Khan, 1992).

As sementes condicionadas em água não conseguiram superar a dormência induzida ou a redução na viabilidade ocasionada pela salinidade do meio germinativo, quando comparadas às sementes que não foram condicionadas. Segundo Braccini et al. (1999), a embebição em água foi considerada prejudicial, retardando a emergência da raiz primária, enquanto o condicionamento osmótico foi eficiente em promover emergência mais rápida do que nas sementes de soja não condicionadas. O efeito prejudicial da rápida embebição das sementes pode ser decorrente da redução da integridade das membranas celulares, provocando perda de nutrientes essenciais, aumento da atividade de microrganismos em função do extravasamento de solutos, ou ainda, baixa disponibilidade de oxigênio, levando ao processo de respiração anaeróbica (Armstrong \& McDonald, 1992).

Segundo Warren \& Bennett (1997), uma das principais vantagens do condicionamento osmótico é promover uma emergência mais rápida e uniforme das plântulas, proporcionando um estande adequado, mesmo em condições adversas. No entanto, as sementes de cássia-do-nordeste condicionadas em água destilada ou nas soluções de PEG, quando colocadas para germinar sob condições de estresse salino, apresentaram valores de tempo de germinação semelhantes àquelas que não foram condicionadas, discordando das observações de Warren \& Bennett (1997).

\section{Conclusões}

1. Há aumento da germinabilidade sob estresse hídrico, e redução da velocidade de germinação, com o uso de soluções de PEG 6000 ou com água destila- 
da, quando o potencial osmótico do meio germinativo foi de - 0,2 a - $0,8 \mathrm{MPa}$.

2. O condicionamento em PEG 6000 ou em água destilada aumenta a porcentagem de germinação e o vigor das sementes em temperaturas subótima e supra-ótima.

3. O condicionamento com PEG 6000 é parcialmente efetivo para superar o estresse salino, aumentando a porcentagem de germinação, nos potenciais de $-1,0$ a $-1,4 \mathrm{MPa}$.

\section{Referências}

ARMSTRONG, H.; McDONALD, M. B. Effects of osmoconditioning on water uptake and electrical conductivity in soybean seeds. Seed Science and Technology, Zurich, v. 20, p. 391-400, 1992.

BARBEDO, C. J.; MARCOS FILHO, J. Tolerância à dessecação em sementes. Acta Botanica Brasilica, São Paulo, v. 12, n. 2, p. 113-204, 1998.

BEWLEY, J. D.; BLACK, M. Seeds: physiology of development and germination. New York: Plenum, 1994. $445 \mathrm{p}$.

BRACCINI, A. L.; REIS, M. S.; SEDIYAMA, C. S.; SCAPIM, C. A.; BRACCINI, M. C. L. Avaliação da qualidade fisiológica de sementes de soja após o processo de hidratação-desidratação e envelhecimento acelerado. Pesquisa Agropecuária Brasileira, Brasília, v. 34, n. 6, p. 10531066, jun. 1999.

BRADFORD, K. J. Manipulation of seed water relations via osmotic priming germination under stress conditions. HortScience, Alexandria, v. 21, n. 5, p. 1105-1112, 1986.

BRAY,C. M. Biochemical processes during the osmopriming of seeds. In: KIGEL, J.; GALILI, G. (Ed.). Seed development and germination. New York: Marcel Dekker, 1995. p. 767-789.

FERNANDES, P. D.; AZEVEDO, N. C.; BARROS, A. D. Pré-embebição, seguida de secagem sobre o desempenho de sementes de caupi, sob condições de déficit hídrico. Pesquisa Agropecuária Brasileira, Brasília, v. 29, n. 1, p. 57-62, jan. 1994.

GRAY, D.; ROWSE, H. R.; DREW, R. L. K. A comparation of two large-scale seed priming techniques. Annals of Applied Biology, London, v. 13, p. 131-181, 1992.
JELLER, H.; PEREZ, S. C. J. G. A. Efeitos dos estresses hídrico e salino e da ação de giberelina em sementes de Senna spectabilis. Revista Ciência Florestal, Santa Maria, v. 11, n. 1, p. 93-104, 2001.

JELLER, H.; PEREZ, S. C. J. G. A. Estudo da superação da dormência e da temperatura em sementes de Cassia excelsa Schrad. Revista Brasileira de Sementes, Brasília, v. 21, p. 32-40, 1999.

JELLER, H.; PEREZ, S. C. J. G. A. Water uptake, priming, drying and storage effects in Cassia excelsa seeds. Brazilian Journal of Biology, São Carlos, v. 63, n. 1, p. 61-68, 2003.

KHAN, A. A. Preplant physiological seed conditioning. Horticultural Review, Edinburgh, v. 13, p. 131-181, 1992.

LABOURIAU, L. G. A germinação de sementes. Washington: Secretaria da OEA, 1983. 173 p.

LANTERI, S.; NADA, E.; BELLETTI, P. Effects of controlled deterioration and osmoconditioning on germination and nuclear replication in seeds of pepper (Capsicum annuum L.). Annals of Botany, New York, v. 77, n. 66, p. 591-597, 1998.

LOPES, H. M.; FONTES, P. C. R.; MARIA, J.; CECON, P. R.; MALAVASI, M. M. Germinação e vigor de sementes de cebola (Allium cepa $\mathrm{L}$.) influenciados pelo período e temperatura de condicionamento osmótico. Revista Brasileira de Sementes, Brasília, v. 18, n. 2, p. 167-172, 1996.

McDONALD, M. B. Seed quality assessment. Seed Science Research, Wallingford, v. 8, p. 265-275, 1998.

MURRAY, G.; SWENSEN, J. B. Emergence of spring and summer planted onions following osmotic priming. HortScience, Alexandria, v. 27, n. 5, p. 409-410, 1992.

NASCIMENTO, W. M. Condicionamento osmótico de sementes de hortaliças: potencialidades e implicações. Horticultura Brasileira, Brasília, v. 16, n. 2, p. 106-109, 1998.

NASCIMENTO, W. M.; CANTLIFFE, D. J.; HUBER, D. J. Endo-beta-mannanase activity and seed germination of thermosensitive and thermotolerant lettuce genotypes in response to seed priming. Seed Science Research, Wallingford, v. 11, n. 3, p. 255-264, 2001.

NASCIMENTO, W. M.; CANTLIFFE, D. J.; HUBER, D. J. Endo-beta-mannanase activity during lettuce seed germination at high conditions. Acta Horticulturae, Wagening, n. 517, p. 107-112, 2000.

Pesq. agropec. bras., Brasília, v. 38, n. 9, p. 1025-1034, set. 2003 
PASSAM, H. C.; KAKOURIOTIS, D. The effects of osmoconditioning on the germination, emergence and early plant growth of cucumber under saline conditions. Scientia Horticulturae, Amsterdam, v. 57, p. 233-240, 1994.

PATANE, C. Influence of temperature on seed germination of sulla sweetvetch (Hedysarum coronarium L.) population collected in a hilly area of southern Italy. Seed Science and Technology, v. 28, n. 3, p. 887-890, 2000.

PRISCO, J. T.; HADDAD, C. R. B.; BASTOS, J. L. P. Hydration-dehydration seed pre-treatment and its effects on seed germination under water stress conditions. Revista Brasileira de Botânica, São Paulo, v. 15, n. 1, p. 3135,1992

SMITH, P. T.; COOB, B. G. Physiological and enzymatic characteristic of primed, re-dried air, and germinated pepper seeds. Seed Science and Technology, Zurich, v. 20, p. 503513, 1992.

SUNG, F. J. M.; CHANG, Y. H. Biochemical activities associated with priming of sweet corn seeds to improve vigor. Seed Science \& Technology, Zurich, v. 21, p. 97-105, 1993.

TAYLOR, A. G.; ALLEN, P. S.; BENNETT, M. A.; BRADFORD, K. J.; BURRIS, J. S.; MISRA, M. K. Seed enhancements. Seed Science Research, Wallingford, v. 8, p. $245-256,1998$.

TRIGO, M. F. O. O.; NEDEL, J. L.; GARCIA, A.; TRIGO, L. F. Efeitos do condicionamento osmótico com soluções aeradas de nitrato de potássio no desempenho de sementes de cebola. Revista Brasileira de Sementes, Brasília, v. 21, n. 1, p. 139-144, 1999.

VILLELA, F. M.; DONI FILHO, L.; SEQUEIRA, E. L. Tabela de potencial osmótico em função da concentração de polietileno glicol 6000 e da temperatura. Pesquisa Agropecuária Brasileira, Brasília, v. 26, n. 11/12, p. 1957-1968, nov./dez. 1991.

WARREN, J. E.; BENNETT, M. A. Seed hydration using the drum priming system. HortScience, Alexandria, v. 32, n. 7, p. 1220-1221, 1997.

YOON, B. Y.; LANG, H. J.; COBB, B. G. Priming with salt solutions improves germination of pansy seed at high temperatures. HortScience, Alexandria, v. 32, n. 2, p. 248 250,1997

ZENGH, G. H.; WILEN, R. W.; SLINKARD, A. E.; GUSTA, L. V. Enhancement of canola seed germination and seedling emergence at low temperature by priming. Crop Science, Madison, v. 34, p. 1589-1593, 1994. 